\title{
Modos de ensinar e conhecer Historia da Psicologia
}

Rosângela Luz Matos $\star$

\begin{abstract}
ReSUMo
Este artigo parte do relato de uma experiência profissional na docência para problematizar o ensino de História da Psicologia na formação de psicólogos. O percurso argumentativo descreve as circunstâncias e os questionamentos que contribuíram para o desenvolvimento de metodologias fundadas na perspectiva genealógica de ensinar e conhecer psicologia. A análise da experiência enfatiza a potência ético-política presente nas atividades de ensino de História da Psicologia, no conjunto das práticas disciplinares dos currículos de graduação para formação de psicólogos.
\end{abstract}

Palavras-chave: docência; práticas de ensino; história da psicologia; genealogia; ética.

\section{Ways to Teach and know History of Psychology}

\begin{abstract}
This article comes from the report of a teaching professional experience to examine the teaching of History of Psychology in the psychologist formation. The argumentative course describes the circumstances and the questions that contributed to the development of methodologies grounded in the genealogical perspective of teaching and knowing psychology. The analysis of the experience emphasizes the ethical politics potential in the activities of teaching psychology history, in the group of disciplinary practices presents in the graduation curriculum of psychology formation.
\end{abstract}

Keywords: teaching; teaching practices; history of psychology; genealogy; ethics.

\footnotetext{
^ Psicóloga. Mestre em Psicologia Social e Institucional pela Universidade Federal do Rio Grande do Sul. Doutorado em Sociologia pela Universidade Federal do Ceará. Atualmente integra o grupo de pesquisa Observatório da Vida Estudantil, no Instituto de Humanidades, Artes e Ciências Prof. Milton Santos e cursa o Pós-Doutorado em Estudos Interdisciplinares sobre Universidade EISU na Universidade Federal da Bahia. Endereço: Universidade Federal da Bahia. Rua Barão de Jeremoabo, s/nº. PAF IV - Ondina. Salvador, BA - Brasil. CEP: 40170-115.

E-mail: rosangela.matos@terra.com.br
} 
Fazer uma análise da experiência de ensinar conhecer psicologia tomando por referência a trajetória acadêmico-profissional traz sempre desafios. Um deles a quem se deve dirigir a narrativa? Outro, como a prática profissional do exercício da docência pode ser narrada enquanto prática de cultura? Como as práticas de ensino, pesquisa e extensão podem compor um texto que comunique a experiência do vir a ser a que todo experimento de docência nos expõe? Como dizer da docência se sua pragmática é também ato de criação, de invenção e contingência? E, como fazer texto daquilo que é também valor? E, ainda, como dar forma ao texto de uma trajetória acadêmica numa dada prática de ensino? Como tornar visível a potência das descontinuidades para a produção de modos de ensinar conhecer História da Psicologia?

Ocorre que a escrita é também um experimento e, precisamente por isso, arrasta consigo algo de imprevisível. Em certa medida, pode-se dizer que o texto diz daquilo que fomos ou fazemos no cotidiano de nossa profissão. Nesta perspectiva, o procedimento narrativo de tornar público aquilo que pertenceu a um grupo, a um lugar, em um dado tempo institucional é, ao mesmo tempo, um experimento de elaboração simbólica do que foi praticado e vivido e um procedimento de liberação da potência dessa experiência para outras ações, outras formas de ensinar e conhecer psicologia. E, numa perspectiva histórica, uma análise da experiência docente ganha valor na medida em que, ao ser deslocado de seu cotidiano, formaliza-se como texto discursivo lançando essa história no plano aberto da produção de sentidos das ciências e dos saberes modernos (MACHADO, 2006).

\section{Fábrica de Perguntas}

No ano de 2001 eu encerrava meu curso de Mestrado na UFRGS ${ }^{1}$ e, ao mesmo tempo, iniciava a primeira experiência na docência. A oferta que recebi era a de ministrar disciplinas de base $^{2}$ no curso de Psicologia: História da Psicologia e Estágio Básico I, o qual deveria oportunizar a integração das aprendizagens de História, Epistemologia em Psicologia, Psicologia Ciência e Profissão e Metodologia da Pesquisa.

$\mathrm{Na}$ ocasião, a proposta pedagógica me pareceu desafiadora, pois não assentava somente na disciplina de história o conjunto de discussões de base que fazem da psicologia um campo de saber. A estrutura curricular oportunizava o deslocamento e a circulação dessas questões noutras disciplinas, de modo tal que pensar a emergência do campo de saber poderia ser feito por vários percursos. Um deles, do ponto de vista dos objetos e métodos de pesquisa que fundam o campo; o outro ,do ponto de vista das normas que instituem as condições de possibilidade para esse saber se instituir como verdade, como discurso sobre o homem; e o último, sobre a circulação e transferência das tecnologias psi para a esfera pública, ou seja, os usos da psicologia.

Sob este ponto de vista entendi que ensinar História da Psicologia poderia ser um experimento criativo e instigante, contudo esta não era a tônica no curso. Descobri, por exemplo, que havia poucos professores que tinham disponibilidade para ministrar essa disciplina e que um dos motivos estava diretamente relacio- 
nado com a recepção que o alunado tinha dessa proposta pedagógica que toma a história como dispositivo de fazer interrogar e situar a emergência de um campo de saber no quadro da epistèmê moderna (FOUCAULT, 1999). Neste contexto, minha empolgação inicial foi contrastada com a contestação dos alunos acerca da "utilidade" de uma disciplina denominada História da Psicologia.

De outra parte, havia um grupo de alunos que tinha interesse em conhecer a história da psicologia, contudo faziam esta demanda numa perspectiva dogmática. Eles queriam uma história que fosse verdadeira: "a verdadeira história da Psicologia". Mais ainda, esses alunos formalizavam a demanda por uma imagem precisa da forma de fazer psicologia: "a verdadeira forma de praticar psicologia".

Essas demandas me forçaram a experimentar a elaboração de variados modelos de ensinar conhecer. ${ }^{3}$ Mas, bem antes de ter clareza de que estava elaborando modelos de ensinar-conhecer nos procedimentos didático-pedagógicos que propunha e praticava com os alunos, vivi intensamente os questionamentos que a mim dirigiam. Num primeiro momento acreditei que eu teria de dar respostas a todas as suas recusas, transformando-as em aceitação, e, aos dogmatismos, transformando-os em dúvidas. Não é preciso dizer que fracassei nessa empreitada. Tentar dar respostas a quem não fez perguntas é encenar um monólogo; é experimento de solidão.

Esta foi uma das primeiras aprendizagens que construí na atividade pedagógica: a experiência de conhecer precisa da curiosidade do aluno, e esta não é uma afirmação retórica. $\mathrm{O}$ semestre letivo seguia e outra forma de olhar para o problema do ensinar-conhecer tornava-se, então, possível. A prática da docência foi encontrando pontos de diálogo com a curiosidade dos alunos por meio de algumas interrogações. Por exemplo: Quais linguagens poderiam ativar suas curiosidades quanto às histórias da psicologia? Ou, quais linguagens acionariam uma inquietação ativa nos alunos para estabelecer conexões entre a vida cotidiana e as psicologias do presente e do passado?

Foi, então, no esteio dessas interrogações, que algumas linguagens do campo das artes passaram a integrar de modo complementar cada atividade de leitura, aproximação e construção de conceitos praticados no programa de ensino da disciplina. Assim, literatura, música, poesia e cinema foram usados como dispositivos para entretecer o diálogo com os fundamentos da psicologia.

O poeta português Fernando Pessoa foi a mais presente referência literária. O poema Segue o teu destino, ${ }^{4}$ que trata do deslocamento da cultura grega para a moderna, em sua relação com o "logos e com a consciência de si", foi escolhido. Este poema está musicado por Sueli Costa e foi gravado por Nana Caymmi em 1985, o que permitiu a leitura e a reprodução do áudio em sala de aula. O poema Autopsicografia é um clássico e foi introduzido para compor as aprendizagens relativas à "descoberta do sentido", introduzida por Freud na constituição do saber psicológico. ${ }^{5}$ Titãs e suas músicas urbanas também foram referências musicais. Entre elas, Comida, Alma Lavada e Não Fuja da Dor. Nas linguagens cinematográficas, várias ofertas foram feitas. Por exemplo, Rain Man ,de Oliver Stone (1988), Laranja Mecânica, de Stanley Kubrick (1971), 
Um estranho no ninho, de Milos Forman (1975) e, é claro, o clássico Freud Além d'Alma , de John Huston (1962). Para introduzir uma perspectiva crítica à hipótese repressiva freudiana, apresentou-se o filme Clamor do Sexo de Elia Kazan (1961), película fiel a primeira interpretação da obra freudiana difundida no pensamento americano e refutada na genealogia da ética e nos estudos sobre a sexualidade desenvolvidos Foucault (2006). Charles Chaplin também foi reproduzido, com especial destaque para Tempos Modernos, de 1936, e os modos de subjetivar com o qual trabalho capitalista opera nos primeiros trinta anos do século XX. Outra referência importante foi o filme Nós que aqui estamos por vós esperamos, de Marcelo Masagão (1998). O diretor problematiza os discursos políticos e científicos que fizeram a história e as micro-histórias de homens e mulheres do século XX, por meio da colagem e reunião intencional de diferentes imagens (fotográficas, filmográficas, midiáticas, televisivas), de textos, áudios e documentários. A psicologia é apresentada pelo diretor como discurso contemporâneo e cuja significação está estreitamente ligada à finitude do homem e às interrogações que as empiricidades da vida provocam nos indivíduos. Nas palavras de Foucault (1999), viver, trabalhar e falar são aqueles fenômenos que põem o homem no centro de toda ciência e saber modernos, mas é a finitude que imprime em seu agir a potência de invenção do presente.

$\mathrm{O}$ uso dessas linguagens nas atividades de sala de aula desestabilizou parcialmente a força dos dogmatismos acionados pelos alunos nos processos de conhecer psicologia. Foi por meio das linguagens artísticas que as posições dogmáticas e retóricas sobre os fundamentos da psicologia mostraram-se mais ligados a uma espécie de não saber formular perguntas do que com uma lógica instrumental estruturada. Pode-se dizer que desde este ponto de vista ocorria ali um encontro. As linguagens não acadêmicas eram uma espécie de "ponto zero", o lugar do "em comum" entre alunos e professor.

Soma-se a esta dimensão da dissolução das oposições platônicas a que alunos e professores estão posicionados na rede de relações institucionais, a proximidade com as linguagens artísticas, o que forçava o processo de ensinar conhecer para uma relação mais ativa com os objetos do mundo, com os objetos de estudo das psicologias, com o cotidiano acadêmico e seus ritos.

A necessidade de estabelecer conexões entre uma narrativa feito imagem - no caso do cinema - e uma narrativa feito língua escrita - no caso de um texto acadêmico - os expunha a procedimentos de conhecer que os forçava a formular interrogações, introduzindo a dúvida como condição de fazer ciência ou para seguir rigorosamente a posição na qual estamos situados epistemologicamente na modernidade, o fundamento de um saber em ciências humanas e sociais.

A dúvida, o não saber como pré-condição para a emergência de um campo de conhecimento ou ciência foi a aprendizagem que este grupo de estudantes estruturou na disciplina de História da Psicologia ${ }^{6}$ e foi o que os conduziu à recepção de textos de história clássicos e contemporâneos. 
Posso dizer que não foi tarefa fácil para os estudantes acolher a noção de que a psicologia não emergiu por um decreto ou genialidade de um sujeito individual, mas que ela é um objeto de cultura, na forma de um discurso acadêmicocientífico, e que, enquanto tal, não está finalizada, pronta, concluída.

Este foi um momento interessante do percurso, pois se a psicologia não está pronta o estudante em formação também passa a fazer parte desse processo de dizer o que é a psicologia, onde estão as psicologias, quem são seus personagens ali, no lugar, na cidade em que ele está estudando.

Com isso, a noção de historicidade acaba por se situar no presente vivido pelos alunos. E, esta noção, amplia-se para a experiência corpórea quando eles passam efetivamente a ser sujeitos da produção de uma história "psi" que existe nos lugares onde eles moram, estudam, divertem-se, trabalham, enfim, vivem.

Dito de outro modo, o exercício de narrar histórias de um lugar, a partir das memórias que ali se apresentam disponíveis, oportunizam ao praticante inscreverse na dimensão do que é fazer história, memoriar, narrar e, por conseguinte, experimentar outros sentidos para as palavras História da Psicologia e seus fundamentos.

Vale dizer, contudo, que esse feito - ser e fazer história - não se deu de uma vez só nos alunos e em mim. Ensinar-conhecer, conhecer-ensinar são lugares mais para habitar do que posições de onde se emite uma informação, palavra ou gesto.

Ademais, estamos falando aqui da micro-história (LEVI, 1992), da história que se escreve desde o mundo das empiricidades da vida; daquelas práticas cotidianas, quase anônimas, e suas infinitas repetições: ler um texto várias vezes com as mesmas pessoas e com pessoas diferentes. Ler um texto conhecido e desconhecer o que nele está escrito. Conversar, falar sobre histórias há muito conhecidas e transmitidas pelas tradições orais e letradas, contudo, vir a saber, por um ouvinte ou novo leitor, que a história está incompleta.

\section{Os Paradoxos do Fora}

De outra parte, neste mesmo ano, 2001, ministrei a disciplina denominada Estágio Básico I e, conforme já disse, seu objetivo seria integrar o conjunto das aprendizagens disponibilizadas no eixo de quatro disciplinas: história, epistemologia, psicologia: ciência e profissão e metodologia da pesquisa científica. Ocorre que no início do segundo semestre letivo deste ano eu havia reunido um expressivo material produzido pelos alunos no ensino de História da Psicologia, destarte ainda não havia compreendido como eles poderiam tomar vida, fazer também sua história no ensino da psicologia.

Foi, então, a atividade didática de supervisão de estágio que me permitiu avançar no desenho de uma metodologia de ensinar-conhecer psicologia, e cujo fundamento foi assentado na indissociabilidade entre ensino, pesquisa e extensão, sendo que a experiência desse estágio concentrou-se mais no deslocamento ensino pesquisa. 
Antes de iniciar essa descrição e discussão, talvez fosse prudente fazer uma consideração acerca dos alunos, sujeitos desta experiência de ensino- aprendizagem. Os estudantes que cursaram a disciplina Estágio Básico I em 2001.2 foram os mesmos que anteriormente haviam estudado História da Psicologia, em 2001.1. Portanto, havia produção de consentimento para o exercício da didática do ensino para além da síntese comunicacional que marca o padrão didático-pedagógico do ensino tecnicista difundido após a reforma de 1968 no ensino brasileiro e que teve grande repercussão no ensino universitário, e, mesmo com a Lei de Diretrizes e Bases de 1996 (BRASIL, 1996), este fundamento não foi questionado.

É preciso dizer, também, que o conflito estava presente nas relações de ensinar-conhecer-ensinar. A desestabilização provocada pela inscrição do sujeito estudante no processo de conhecer produzia muitas angústias, pois aqueles experimentos metodológicos os aproximavam também das incertezas profissionais e dos discursos não hegemônicos, o que colocava em xeque a escolha profissional: fetiche do ensino de $3^{\circ}$ grau no Brasil que desconsidera a produção de conhecimento no campo das ciências humanas e sociais e afirma esses sujeitos como praticantes de algum ofício.

$\mathrm{Na}$ disciplina de História, por exemplo, as desestabilizações foram produzidas, sobretudo, pelo exercício de não dar respostas e conduzi-los a formalizar perguntas, terem dúvidas. A atividade didático-pedagógica condizia-se, no máximo, de modo a oferecer deslocamentos de linguagens de modo a deixar o alunado em condição de implicar-se na construção de suas aprendizagens. Já no estágio básico a proposta era a de levá-los a experimentar aprendizagens descentradas da sala de aula, oferecendo-lhes mobilidade com o fora. Mas aí a pergunta pedagógica que se apresentava era outra: o que seria o fora da sala de aula?

Noutra dimensão, eu me perguntava: como mobilizar nos alunos desejo de ir a algum lugar que não fosse a sala de aula? Some-se a isso o trabalho pedagógico realizado na disciplina de História, cujo objetivo foi precisamente provocar qualidade crítica nos modos de adesão dos estudantes as propostas didáticas.

O caminho que aos poucos foi se desenhando foi o de levar os alunos a transformar suas ânsias por respostas rápidas sobre a psicologia em perguntas de pesquisa. Perguntas capazes de conduzí-los ao mundo, aos lugares em que a psicologia e os psicólogos estão. Mas a ação didática exigia agora fazer uma pergunta que provocasse inquietação suficiente para pôr os estudantes em movimento, para fazê-los olhar para fora da sala de aula, para o bairro em torno da universidade; para fazê-los querer localizar equipamentos públicos e privados nos quais a psicologia estivesse presente.

Aos poucos, fui conseguindo formular uma pergunta cuja forma de apresentação provocou mais pela impossibilidade de respostas (apriorísticas e retóricas) do que pela imagem, representação ou conceito que enunciava. A interrogação era: o que pode a psicologia? Dar resposta a esta pergunta exigia inscrição temporal, contextual e pessoal num dado campo empírico. O que pode a psicologia em relação à que? Quando? Em que circunstâncias e contexto social, político, 
econômico, arquitetônico etc.? O valor desta pergunta estava precisamente na orientação que conferia ao pensamento: ir para fora de si, buscar a resposta junto às práticas humanas vividas numa dada localidade, instituição, individualidade.

Cada vez mais tenho compreendido que perguntar é talvez o experimento que pode nos conduzir a constituir um saber sobre um objeto, um fenômeno ou uma experiência vivida. Sobremaneira é preciso compreender que a potência do pensamento não reside em alguma interioridade, senão que na ação de expandirse. É este sair de si, ir para fora que enreda o sujeito com o que há de vivo no mundo (DIAS, 2007). Então, além de formular uma pergunta capaz de pôr o pensamento em ação seria preciso contar com o apoio de alguns instrumentos que auxiliassem nos procedimentos de registro das conversações praticadas, das imagens capturadas, das informações obtidas etc.

Este foi o modo pelo qual conduzi a inserção dos alunos do Estágio Básico I em psicologia. $\mathrm{O}$ fora da sala de aula apresentou-se, inicialmente, na forma de uma pergunta paradoxal. No momento seguinte, apresentei um Plano de Ensino com algumas possibilidades de inserção local, institucional, profissional, conceitual ou paradigmáticas. Logo a seguir, cabia discutir com eles as formas pelas quais se faria o estágio e seus diálogos com modos de fazer pesquisa.

Este foi o momento em que aquela pergunta pedagógica retornou mais forte: o que seria o fora da sala de aula? Um primeiro movimento com o pensamento indicava que esse procedimento, o de deslocar as aprendizagens para o fora da sala de aula, não criava problemas contundentes no currículo. Exigia, contudo, atores qualificados para compor a cena de aprendizagem fora da instituição de ensino. Isto posto, a ideia de aprendizagens construídas em polifonia (LAZZAROTTO, 2009) e por práticas de circulação na cidade (FREITAG, 2002; MAGNANI, 2002), em instituições públicas e privadas, movimentos sociais, hospitais, prisões, entidades de classe, entre outros foi encontrando sustentação entre os professores e os alunos do curso.

Assim, um conjunto de instituições locais ${ }^{9}$ foi acionado para acolher os jovens estudantes na condição de "pesquisadores", perguntadores. Ainda, um grupo de profissionais psicólogos e não psicólogos implicados com temas de saúde pública foram identificados e convidados a colaborar com os alunos, através de fóruns denominados "Diálogos". Esses encontros eram realizados via REDE através de uma página da internet e de e-mail de grupo, ou em situação presencial, ${ }^{10}$ ou, ainda, na participação em atividades acadêmico-científicas realizadas no período em que o estágio estava em vigência. ${ }^{11} \mathrm{~A}$ estrutura de acompanhamento do estágio se fez por meio de supervisões coletivas, por grupos de trabalho - GTs (nome dado a cada tema, área de atuação ou problemática escolhida), de modo que, ao longo do primeiro mês de atividades, o alunado pudesse efetivar exercícios de reflexão, de construção de instrumentos de entrevista, sempre subsidiados por bibliografia condizente e referenciados pela escrita como instrumento capaz de conter a proposição da experiência para a qual estavam se preparando. 
Para todo artigo lido era solicitado um pequeno texto de quatro ou cinco parágrafos. Estes artigos eram lidos nos GTs e discutidos entre os alunos. Ao professor cabia remeter a escrita, por eles construída, a outro artigo que pudesse dialogar com a aprendizagem ali delineada.

Ao longo do segundo mês de atividades de estágio os alunos passaram a se dirigir para as atividades de observação, acompanhamento ou entrevistas no campo escolhido para a prática do estágio. A prática da supervisão neste período se ocupava com orientações acerca das formas de registro daquilo que ia sendo observado, das práticas de acompanhamento e mesmo entrevistas em processo.

No terceiro mês de atividades, os alunos passavam a se concentrar mais na revisão teórica do tema, área de atuação ou problemática estudada, procurando reunir elementos para uma síntese compreensiva do aprendido. Nos encontros de supervisão, as atividades se vinculavam à discussão da bibliografia consultada - os conceitos e teorias, na estruturação dos textos produzidos pelos GTs sobre suas áreas de estudo, no debate das questões emergentes, no cruzamento das informações registradas na experiência de campo com aquelas encontradas na bibliografia consultada.

Finalmente no quarto mês de atividades o alunado se dedicava a construir o documento chamado Relatório de Estágio, e na prática da supervisão se priorizava a orientação da discussão construída pelo aluno no texto escrito, evidenciando a aprendizagem construída na perspectiva da tradição acadêmica.

Ao final do estágio, foi oferecida a possibilidade do aluno participar daquilo que foi chamado avaliação da aprendizagem construída. Disponibilizou-se um roteiro com algumas perguntas fechadas e outras abertas para que ele efetuasse a avaliação do processo de aprendizagem proposto ao longo do estágio. De um universo de 80 alunos que participaram da disciplina Estágio Básico I, 49 se disponibilizaram a participar do processo de avaliação.

A avaliação realizada indicou que dos métodos propostos aqueles que mais contribuíram para o processo de construção do conhecimento foram: as atividades de saída a campo, entre elas, entrevistas, visitas e acompanhamento das atividades dos profissionais nos seus locais de trabalho (do total de 49 avaliações um total de 33).

Pode-se perguntar: qual o sentido desta avaliação? Qual sua potência para a prática da docência? Qual a função dessa avaliação num contexto de introduzir a dúvida como fio condutor da ação de intervir em favor de um processo em construção?

Sobremaneira a avaliação proposta orientava-se para afirmar uma dimensão de valor acerca dos processos de aprendizagens vividos, praticados, corporificados pelos alunos e pela professora. Pensar sobre o que faz aprender, refletir sobre a experiência, dar para isto palavra, verbo é uma prática de si no sentido que Foucault (apud PRADO FILHO, 2009) propõe. 
Ademais, a proposta de avaliar as aprendizagens construídas permitiria uma aproximação com o debate em torno da produção das subjetividades, de discursos e práticas sociais para os quais a psicologia deve estar atenta, ao menos na formação de profissionais psicólogos, ou isto que estou denominando de "os paradoxos do fora".

Regina Benevides de Barros (2005, p. 23) introduz este debate circunscrevendo a separação entre clínica e política, presente na formação de psicólogos, como um dos modelos de ensinar-conhecer que deve ser questionado. Propõe a retomada de algumas noções da clínica, para que se problematize o campo das práticas "psi” e da formação em psicologia. Dá especial ênfase ao paradigma, cuja prática discursiva, ora em voga, expressa-se pela afirmação: "ciência e política são duas esferas separadas e de que as práticas "psi” ao se encarregarem do sujeito não devem tratar de questões políticas".

A autora sublinha esta afirmação para explicitar que a consequência dessa separação está expressa na dicotomia interioridade/exterioridade, indivíduo/ social e que eles são apenas modelos, são modos formalizados por uma dada tradição, e podem ser questionados, podem ter seus fundamentos interrogados.

Neste sentido, os paradoxos do fora ou estar no "plano da subjetivação", como ela propõe, seria um modo para a produção de sujeitos autônomos, criativos, críticos e afeitos a perguntação. Se houve a experiência do fracasso em alguns momentos do processo de ensinar-conhecer, houve também esta descoberta de que ensinar-aprender se faz em espaços públicos, pelo uso público daquilo que é de todos nós: as práticas de cultura, inclusive as científicas, as profissionais.

O que mais interessa aqui destacar é este aspecto de produção do sujeito, de um sujeito autônomo (Eirado; Passos, 2004) [...] E aqui já podemos enunciar que entendemos a experiência clínica como a devolução do sujeito ao plano da subjetivação, ao plano da produção que é plano do coletivo. O coletivo, aqui, bem entendido, não pode ser reduzido a uma soma de indivíduos ou ao resultado de um contrato que os indivíduos fazem entre si. [...] É aí que entendemos se dar a experiência da clínica: experimentação no plano coletivo, experimentação pública (BENEVIDES DE BARROS, 2005, p. 22-23).

Apenas para reforçar o alerta que Benevides de Barros (2005) nos faz, vale lembrar aqui que a interrogação do que está naturalizado por meio de ações de experimentação viva, empírica são um dos movimentos da proposição nietzscheana de Transvaloração de Todos os Valores, precisamente aquilo que o autor denomina de Reversão do Platonismo (NIETZSCHE, 1992, 1998). 


\section{Dos modos históricos de contar a Historia da Psicologia}

Segundo a "tradição", não há dúvidas sobre o que vem a ser "O Método Histórico" de uma dada prática de cultura, ensinar-conhecer, por exemplo. Ocorre que esta pragmática, a de ensinar-conhecer, se orientou mais pela noção de gênese do que pela noção de finalidade, utilidade, significado a ser transmitido, saber a ser reproduzido.

Reside aí toda a diferença.

Ensinar-conhecer foi praticado numa perspectiva genealógica, portanto, que interroga as origens, ${ }^{12}$ as verdades instituídas, os fundamentos, os valores atribuídos as práticas já em reprodução. Mas o faz na medida em que põe alunos, professor e profissionais psicólogos, em situação de experimentação, de empiria, de viver um dado modo de fazer histórias da psicologia. Psicologia esta local, regional e também universal, pois os praticantes desse fazer é que falam, nomeiam, descrevem, historiam as psicologias em ação.

Para Foucault (1999), as possibilidades de verdade e de produção de conhecimento se dão de modos diferentes, no terreno das ciências e no dos saberes. Conforme explica Machado (2006), o desenho epistemológico das ciências modernas permitiu a Foucault (1999) afirmar que as regiões do triedro ${ }^{13}$ cobertas pelas ciências da vida, da natureza ou pelas filosofias são aquelas nas quais historicamente pratica-se uma epistemologia normativa e por meio da qual se busca garantir e conferir legitimidade e verdade ao conhecimento.

Noutra condição de possibilidade, os saberes, àqueles que emergem das ciências humanas e sociais, têm seu modo epistemológico próprio, dado que não estão alojados em nenhuma das regiões visíveis e/ou exteriores do triedro. Os saberes que "gravitam em torno da questão do homem", diz Machado (2006), ocupam o volume interno do triedro, portanto localizam-se numa região nebulosa do triedro dos saberes, arrastando consigo a impossibilidade de objetividade e de verdade, no sentido científico que as ciências da vida e da natureza objetivaram.

Foucault (1999) vai denominar, então, de Histórico o método ou a epistèmê que orienta a produção de saberes no terreno das ciências humanas e sociais. $\mathrm{O}$ método histórico seria este que conduz o pesquisador a esta zona nebulosa do triedro, região em que os saberes históricos sobre o homem estão alojados sob diferentes combinações e abertos para composições, para "reescrever a história".

Nesta perspectiva, ensinar-conhecer História da Psicologia exigiria o interrogar-se sobre qual posição de lugar o professor praticante está a habitar no desenho epistemológico das ciências modernas. Qual a historicidade de sua formação em psicologia? Qual a inscrição desse conhecimento no triedro dos saberes? Qual a função desta historicidade para o presente das práticas psicológicas? Quais suas formas de apresentação no cotidiano das relações sociais, políticas, institucionais? Quais seus usos para a produção da vida dos homens? 
A perspectiva de um método histórico próprio às ciências humanas e sociais, como dito anteriormente, oportuniza aos saberes abrirem-se para o terreno da invenção ou composição. Dirigirem-se mais além da transmissão e reprodução, arriscarem-se no plano da invenção. Não só desconhecimento, mas também recobrimento, reordenamento e experimentação na pronúncia dos sons ou línguas que se conformam no encontro dos saberes que estão nessa região do invisível, na epistèmê moderna.

No caso da psicologia, teríamos aqui autorização e legitimidade para orientar nossa pragmática para o terreno da ética e das práticas de cultura, de modo que os discursos sobre o humano possam acolher uma analítica do valor. O valor da psicologia para os homens do tempo presente. Qual a potência da psicologia para fazer avançar o valor da vida humana por sobre o valor do capital econômico e a ética do capitalismo?

Nas Políticas Públicas, por exemplo, poderíamos perguntar: como a psicologia pode criar espaço para interrogar a "falta" como pressuposto que orienta a relação das instituições públicas com as populações a que assiste? Quais saberes a psicologia pode trazer para o cotidiano da formação de psicólogos com vistas a arriscar-se na arte de reinventar novos modos de fazer psicologia e resistir à hegemonia das práticas disciplinares e de controle das subjetividades? Como afirmar a produção do saber 'psi' em favor da liberação dos sujeitos de dogmatismos, misticismos de toda ordem e fetichismos capitais, entre eles o consumo da psicologia como mercadoria.

Essas seriam algumas questões que o horizonte aberto por Michel Foucault pode nos trazer. É importante referir que a analítica do autor oferece suporte para aquelas questões que tomam por referência conhecer as psicologias orientadas para a problematização do valor da vida, das práticas de cultura, sejam elas o trabalho, as artes, ou a vida cotidiana.

Dito de outro modo, a psicologia pela posição e condição de sua emergência no desenho da episteme moderna traz consigo a possibilidade de fazer visível o devir dos sujeitos; o vir a ser especular, visível na imagem que as ciências da vida, da linguagem e do trabalho, bem como as ciências da natureza e as filosofias, projetam sobre o homem no volume interno do triedro dos saberes. Mais ainda, a psicologia em diálogo com uma dessas ciências potencializa a noção de autoria, de autonomia ou resistência dos sujeitos na constituição de sua experiência psicológica, social, política, ética, moral.

\title{
Notas
}

\begin{abstract}
${ }^{1}$ Departamento de Psicologia Social e Institucional, Curso de Psicologia. Programa de PósGraduação em Psicologia Social e Institucional - Universidade Federal do Rio Grande do Sul.

${ }^{2}$ Centro Universitário Franciscano - UNIFRA, 2001.

Se tomarmos o mundo grego como referência para afirmar a emergência de uma educação superior orientada como prática pública destinada à formação de cidadãos vamos encontrar diferentes modelos de ensinar e conhecer por eles desenvolvidos. A Paidéia, o Gymansium e o Lyceum expressam formalizações de diferentes modelos elaborados para a educação de crianças, jovens e adultos no mundo grego de diferentes períodos. A educação por meio de jogos, a educação espiritual ligada as musas, a educação do corpo e a educação moral desenvolveram-se conformando
\end{abstract}


níveis de ensino. A educação superior é tributária do período socrático, mas sua organização em ginásios e liceus tem em Platão e Aristóteles seus mais conhecidos representantes. O fundamental consiste em que a educação superior não é caracterizada como uma relação mestre-aluno, na qual a transmissão e a aprendizagem de uma técnica ou ofício são o objetivo. Ao contrário, a educação superior voltava-se para o ato de conhecer, entre os quais pode-se destacar a prática de "diálogos" e a "escrita peripatética". Para conhecer mais sugere-ser: L'Education Athénienne de Paul Girard e Historia da Filosofia da coleção Os Pensadores.

${ }^{4}$ Este poema é de autoria do heterônimo Ricardo Reis.

Sobre esta afirmação ver Foucault, 2002.

${ }^{6}$ Curso de Psicologia da UNIFRA. No curso, era prática, o professor ter mais de uma turma de uma mesma disciplina. No caso, eu ensinava um grupo de alunos no noturno e outro do matutino. ${ }^{7}$ Os textos clássicos eram aqueles difundidos na obra de Schultz, D. e Schultz, S. (1981), em especial as traduções dos manifestos ou artigos científicos que fundaram os diferentes projetos de psicologia. Os textos contemporâneos disponibilizados foram os de Figueiredo (1991; 1995; 1996; 2000; 2002). Sobre história da psicologia no Brasil foi disponibilizada a produção do grupo Clio-Psyché, coordenado pela profa. Heliana de Barros Conde Rodrigues e Ana Maria Jacó-Vilela (1999), da UERJ, e que àquela época já haviam publicado um livro cujo título é Histórias da Psicologia no Brasil,.

${ }^{8}$ A cidade-sede da instituição de ensino, Santa Maria, está localizada no centro do estado do Rio Grande do Sul, a 286 km da capital, Porto Alegre, e com população estimada em 250 mil habitantes. Sua constituição está ligada com as colônias italianas instaladas na região no inicio do século XX. Costuma-se dizer que esta é a $3^{\mathrm{a}}$ colônia italiana no Estado. Posteriormente, a cidade ganha importância pela localização privilegiada e instalação da rede ferroviária nacional, por meio da qual a produção de toda a região escova, nos idos do primeiro período de industrialização do Brasil e expansão da ferrovia para o abastecimento dos grandes centros urbanos. Ao mesmo tempo, a cidade tem importância pela tradição na formação de jovens brasileiros no serviço militar, e entre os anos 1940 e 1950 transformou-se no mais importante pólo para a formação e a carreira no serviço militar brasileiro. Posição esta modificada, somente após o golpe militar de 1964. A tudo isto somado, nos anos 1960, uma universidade federal (UFSM) é ali instalada e somente em 1997 o curso de psicologia é inaugurado. A instituição de ensino, objeto deste artigo, é uma instituição católica, de uma das congregações que ali se instalaram com as colônias italianas. Tem tradição no ensino fundamental e médio e nos anos 1990, com a expansão do ensino superior, inicia a oferta de vários cursos de graduação, entre eles o de Psicologia no ano de 2000. O alunado desta instituição, em sua maioria, provinha de classes médias, de toda a região e cuja riqueza originalmente esteve assentada na produção rural da região, em especial agricultura de extensão e agropecuária, entre essas o plantio de soja, arroz, e gado de corte de alto padrão. Havia, ainda, alunos cuja origem era a de famílias ligadas as profissões que o serviço militar de carreira mantinham na cidade. O curso de Psicologia também registrava alunos cujas famílias estavam ligadas ao setor serviços, em fase de expansão nos anos 1990 e 2000, em várias regiões do Brasil. Além desses, a cidade recebi alunos oriundos de famílias ligadas as carreiras públicas, tais como servidores da educação, agricultura, saúde e outros segmentos ali instalados.

${ }^{9}$ Secretaria Municipal de Saúde, $4{ }^{\text {a }}$ Coordenadoria Regional de Saúde, Conselhos Municipais de Saúde, de Entorpecentes, do Idoso, dos Direitos da Criança e do Adolescente e Conselhos Tutelares de Santa Maria. Hospital Universitário - UFSM/ "Turma do Ique", Movimento Nacional de Meninos e Meninas de Rua, PACTO - Pastoral do auxílio comunitário ao toxicômano, PROAME - Programa de apoio a meninos e meninas, FEBEM e Fundação CASA.

${ }^{10}$ Entrevistas via Internet: Departamento de Psicologia Social e Institucional e departamento de Psicanálise e Psicopatologia do Instituto de Psicologia da UFRGS, em especial os professores Analice de Lima Palombini, Edson Luiz André de Souza, Sergio Antonio Carlos e Gislei Lazzarotto. Eliane Jover, Educardo Pelliccioli e Laura Lamas Gonçalves, Acompanhantes Terapêutico-http:// www.psicologia.ufrgs.br/departamentos/depto_social/programa_acompanhamento_terapeutico. pdf.

Luiz Ziegelman, Coordenador do Serviço de Saúde Integral do Hospital Estadual Nossa Senhora da Conceição (GHC), de Porto Alegre. Rosa Mayer - Escola de Saúde Pública/RS. Fernanda Kerbes - PMPOA. Fernanda Bocco, estagiária do Projeto CORAG/UFRGS - qualificação de jovens e adolescentes em situação de risco social para empreendimentos autogestionários.

Entrevistas presenciais: Aline P. Schaurich - Febem/Santa Maria/RS, Bernadete dos Santos Pereira e Carlos Nascimento - Coordenadoria de Saude Mental na região, César Brid - Centro de 
Saúde Mental do Cento Social Urbano, Cesimari Antunes - Santa Casa de Misericórdia - Alegre/ RS, Edenir Teixeira e Patrícia Ilha - Hospital de Caridade Astrogildo Azevedo, Ivone Fontanella - Hospital Santo Antonio - São Sepé/RS, Mara Helena Ribeiro Souza - Assessora Ministério da Saúde para atuação dos psicólogos em Hospitais.

${ }^{11}$ Atividades acadêmico-científicas: JORNADA DO PÓS-GRADUAÇÃO EM PSICOLOGIA - PUCRS, Porto Alegre 2001; CICLO DE PALESTRAS CONHECENDO DIFERENTES EXPERIÊNCIAS E IN(TER)VENCCÕES EM GRUPOS E COLETIVOS, Santa Maria UNIFRA, 2001; $1^{\text {a }}$ SEMANA DE PSICOLOGIA APRENDENDO O FAZER PSICOLÓGICO: CAMINHOS E DESAFIOS. Santa Maria, UNIFRA, 2001; III JORNADA DE SEXUALIDADE da UFSM, 2001; VIII SEMANA GAÚCHA EM SANTA MARIA CONTRA O USO INDEVIDO DE DROGAS, UNIFRA, 2001; I CONFERÊNCIA INTERMUNICIPAL E MICRORREGIONAL DE SAÚDE MENTAL de São Pedro do Sul/RS, 2001; V ENCONTRO NACIONAL DO MOVIMENTO DA LUTA ANTIMANICOMIAL, 2001; $2^{\text {a }}$ CONFERÊNCIA MUNICIPAL DE SAÚDE MENTAL, Santa Maria, 2001; III JORNADA DO NÚCLEO PSICANALÍTICO de Santa Maria, 2001.

Trabalhos apresentados em congresso após a conclusão das disciplinas: 1. ZANINI, G.; MATOS, R. L. Idoso e a institucionalização da saúde mental. In: XXI ENCONTRO NACIONAL DA ABRAPSO, 2001, Florianópolis. www.abrapso.org.br e 2. BELTRAME, B.; GRAPEGGIA, J.; GEORG, R. MATOS, R. L.. Como os Psicólogos tratam hoje da loucura. In: XXI CONGRESSO NACIONAL DA ABRAPSO, 2001, Florianópolis. www.abrapso.org.br.

${ }^{2}$ Conforme Castro (2009, p. 306), interrogar as origens de algum objeto ou prática consiste em pôr em dúvida a "essência exata das coisas em sua identidade imóvel". Nietzsche é aqui a inspiração de Foucault. A essência das coisas, nada mais é do que "máscaras"; "atrás de cada coisa há outra ou outras coisas" (CASTRO, 2009, p. 306). O genealogista operaria seus exercícios de análise na direção do externo e do acidental, para as diferenças e para as peripécias (CASTRO, 2009, p.306). Este autor também refere que um dos argumentos para esta diferenciação consiste na análise etimológica da palavra "arqué" de uso cuidadoso na obra de Nietzsche e a partir da qual Foucault orienta sua proposição de genealogia. Ele opõe "Ursprung" - origem a "Herkunft" proveniência e "Entstehung" - emergência. Uma referência para esta problematização pode ser encontrada em O Nascimento da Tragédia ou Helenismo e Pessimismo de Nietzsche (1992) e Nietzsche, Freud e Marx. Theatrum Philosoficum de Foucault (1980).

${ }^{3}$ Foucault (1999) apresenta as ciências e os saberes que conformam a epistémê moderna numa figura geométrica denominada Triedro dos Saberes. Numa das faces do triedro encontrar-se-iam as filosofias e a teologia, noutra as ciências da natureza e, na terceira face desta figura, as ciências da vida, do trabalho e da linguagem que se conformaram no século XIX. As ciências humanas e sociais, neste desenho, teriam sua emergência possível desde os efeitos de relação entre os diferentes domínios do saber, representados nas diferentes faces do triedro. Dessas relações emergiriam as ciências humanas e sociais, com características e objetivos ligados aos domínios de saber que a elas deram origem. Seu lugar no triedro seria o dos interstícios entre um e outro saber, na medida em que uma relação de produção entre eles se estabelecesse. Para maior detalhamento, ver o capítulo "As Ciências Humanas e Sociais" da obra referida.

\section{REFERÊNCIAS}

ANTUNES, A.; BRITO, S.; FROMER, M. Comida. Intérprete: Titãs. In: TITÃS. Jesus não tem dentes no país dos banguelas. [S.1.]: WEA, 1987. 1 CD. Faixa 2.

BENEVIDES DE BARROS, R. Psicologia e o sistema único de saúde: quais interfaces? Psicol. Soc., Porto Alegre, v. 17, n. 2, p. 21-25, ago. 2005. Disponível em: $\quad<$ http://www.scielo.br/scielo.php?script=sci_arttext\&pid=S0102$71822005000200004 \& \operatorname{lng}=$ pt\&nrm=iso $>$. Acesso em: 30 ago. 2010.

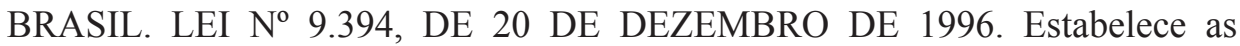
diretrizes e bases da educação nacional. Disponível em: http://www.planalto.gov. 
br/ccivil 03/leis/L9394.htm. Acesso em: 15 jul. 2010.

CASTRO, E. Vocabulário de Foucault: um percurso pelos seus temas, conceitos e autores. Tradução de Ingrid Müller Xavier. Revisão teórica: Alfredo Veira-Neto e Walter Omar Kohan. Belo Horizonte: Autêntica, 2009.

CENTRO UNIVERSITÁRIO FRANCISCANO - UNIFRA. Projeto Pedagógico do curso de Psicologia. Santa Maria, 2001.

CLAMOR do sexo. Direção: Elia Kazan. USA: NBI Productions; Newton Productions, Warner Bros. Pictures, 1961. 1 DVD.

DIAS, R. M. Nietzsche educador. São Paulo: Scipione, 2007.

EIRADO, A.; PASSOS, E. A noção de autonomia e a dimensão do virtual. Psicol. estud., Maringá, v. 9, n. 1, p. 77-85, abr. 2004. Disponível em: <http://www. scielo.br/scielo.php?script=sci_arttext\&pid=S1413-73722004000100010\&lng= pt\&nrm=iso >. Acesso em: 30 ago. 2010.

FIGUEIREDO, L. C. M. Matrizes do Pensamento Psicológico. 7. ed. Petrópolis: Vozes, 1991.

FIGUEIREDO, L. C. M. Modos de Subjetivação no Brasil e outros escritos. São Paulo: EDUC/Escuta, 1995.

FIGUEIREDO, L. C. M. Revisitando as Psicologias: da epistemologia à ética das práticas e discursos psicológicos. 2. ed. São Paulo: EDUC; Petrópolis: Vozes, 1996.

FIGUEIREDO, L. C. M.; SANTI, P. L. R. Psicologia uma (nova) introdução. 2. ed. São Paulo: EDUC, 2000.

FIGUEIREDO, L. C. M. A invenção do Psicológico. Quatro séculos de subjetivação 1500 -1900. 5. ed. São Paulo: EDUC/Escuta, 2002.

FOUCAULT, M. Nietzsche, Freud e Marx: theatrum philosoficum. Tradução de Jorge de Lima Barreto. Porto: Biblioteca Nova Crítica, 1980.

As ciências humanas. In: . As palavras e as coisas: uma arqueologia das ciências humanas. 8. ed. São Paulo: M. Fontes, 1999. p. 475-536.

FOUCAULT, M. A Psicologia de 1850 a 1950 (1957). In: MOTTA, M. B. (Org.). Problematização do sujeito: Psicologia, Psiquiatria e Psicanálise. Tradução de Elisa Monteiro. 2. ed. Rio de Janeiro: Forense Universitária, 2002. p. 133-151. Coleção Ditos \& Escritos, v. 1. 
FOUCAUlT, M. Ética, Sexualidade, Politica. Tradução de Elisa Monteiro e Inês A. D. Barbosa. 2. ed. Rio de Janeiro: Forense Universitária, 2006. Coleção Ditos \& Escritos, v. 5.

FREITAG, B. Cidade dos Homens. Rio de Janeiro: Tempo Brasileiro, 2002.

FREUD além d'alma. Direção: John Huston. [S.1.]: Bavaria Film, 1962. 1 DVD.

GIRARD, P. L'Education Athénienne au $V$ et au IV siècle avant J.-C. Paris: L. Hachette, 1889. Disponível em <http://ia700402.us.archive.org/11/items/ lducationath00girauoft/lducationath00girauoft.pdf $>$. Acessado em 30 ago. 2011. Digitized by the Internet Archive in 2009 with funding from University of Ottawa.

JACÓ-VILELA, A. M.; JABOUR, F.; RODRIGUES, H. B. C. (Org.). Histórias da Psicologia no Brasil. Rio de Janeiro: UERJ/NAPE, 1999.

JOBIM, T. Autopsicografia. Intérprete: Tom Jobim. In: JOBIM, T. et al. A música em Pessoa. Rio de Janeiro: Biscoito Fino, [1985] 2002. CD. Faixa 15. [adaptação poema de Fernando Pessoa por Tom Jobim].

LARANJA Mecânica. Direção: Stanley Kubrick. [S.l.]: Warner Bros, Pictures, 1971. 1 DVD.

LAZZAROTTO, G. D. R.; PALOMBINI, A.; MARASCHIN, C. M. Currículo como dispositivo de invenção: práticas coletivas e singulares na formação do psicólogo. In: MESA REDONDA DO CONGRESSO BRASILEIRO DE PSICOLOGIA: CIÊNCIA E PROFISSÃO. São Paulo, Anais ... 2002. Disponível em: <http://www.cienciaeprofissao.com.br/congre/downloads.asp>. Acesso em: 30 de ago. 2010.

LAZZAROTTO, G. D. R. Pragmática de uma língua menor na formação em psicologia: um diário coletivo e políticas juvenis. 2009. Tese (Doutorado)Universidade Federal do Rio Grande do Sul, Porto Alegre, 2009.

LEVI, G. Sobre a micro-história. In: BURKE, P. (Org.). A escrita da história: novas perspectivas. São Paulo: UNESP, 1992. p. 133-161.

MACHADO, R. Foucault, a ciência e o saber. 3. ed. Rio de Janeiro: J. Zahar, 2006.

MAGNANI, J. G. C. De perto e de dentro: notas para uma etnografia urbana, São Paulo. Revista Brasileira de Ciências Sociais, São Paulo, v. 17 n. 49, p. 11-29, jun. 2002. Disponível em <http://www.scielo.br/scielo.php?script=sci arttext\&pid $=$ S0102-69092002000200002\&lng $=$ pt\&nrm=iso>. Acesso em: $3 \overline{0}$ ago. 2010 . 
MELLO, B. et al. Alma Lavada. Intérprete: Titãs. In: TITÃS. A Melhor Banda de Todos os Tempos. Manaus: Abril Music, 2001. 1 CD. Faixa 15.

MELLO, B. et al. Não fuja da dor. Intérprete: Titãs. In: TITÃS. A Melhor Banda de Todos os Tempos. Manaus: Abril Music, 2001. 1 CD. Faixa 8.

NANA, C. Segue o teu destino. Intérprete: Nana Caymmi. In: JOBIM, T. et al. A música em Pessoa. Rio de Janeiro: Biscoito Fino, [1985] 2002. CD. Faixa 2. [adaptação poema de Ricardo Reis por Sueli Costa].

NIETZSCHE, F. O Nascimento da Tragédia: ou Helenismo e Pessimismo. Tradução, notas e posfácio J. Guinsburg. 2. ed. São Paulo: Companhia das Letras, 1992.

NIETZSCHE, F. Genealogia da Moral: uma Polêmica. São Paulo: Companhia das Letras, 1998.

NÓS que aqui estamos por vós esperamos. Direção: Marcelo Masagão. [S.1.]: Agencia Observatorio, 1998. 1 DVD.

ABRÃO, B. S. (Org.). Historia da Filosofia. São Paulo: Nova Cultural, 1999. Coleção os Pensadores.

PRADO FILHO, K. Considerações acerca do cuidado de si mesmo no contemporâneo. In: TEDESCO, S.; NASCIMENTO, M. L. (Org.). Ética e Subjetividade: novos impasses no contemporâneo. Porto Alegre: Sulina, 2009. p. 231-245.

RAIN Man. Direção: Barry Levinson. USA: MGM, 1988. 1 DVD.

SCHULTZ, D. P.; SCHULTZ, S. E. História da Psicologia Moderna. São Paulo: Cultrix, 1981.

TEMPOS modernos. Direção: Charles Chaplin. [S.l.]: Charles Chaplin Productions, 1936. 1 DVD.

UM ESTRANHO no ninho. Direção: Milos Forman. [S.1.]: Fantasy Films, 1975. 1 DVD.

Recebido em: 07 de setembro de 2010 Aceito em: 14 de setembro de 2011 